\title{
ERRATUM TO: Cardiac Troponins in Low-Risk Pulmonary Embolism Patients: A Systematic Review and Meta-Analysis
}

\author{
Omar S. Darwish, MS, DO ${ }^{1 *}$, Abdullah Mahayni ${ }^{1,2}$, Mukti Patel, MD¹, Alpesh Amin, MBA, MD
}

'University of California, Irvine, UCI Medical Center, Orange, California; ${ }^{2}$ Mr. Mahayni is now with King Saud bin Abdulaziz University for Health Sciences, University in Riyadh, Saudi Arabia.

The authors would like to make the following corrections to their manuscript, Cardiac Troponins in Low-Risk Pulmonary Embolism Patients: A Systematic Review and Meta-Analysis (doi: 10.12788/jhm.2961), published online first April 25, 2018 (all corrections in bold):

- The last sentence of the results section in the abstract should read: The pooled likelihood ratios (LRs) for all-cause mortality were positive LR 2.04 [95\% Cl, 1.53 to 2.72] and negative LR 0.72 [95\% Cl, 0.37 to 1.40$]$.

- In the "All studies pooled" of the last row of Table 2, Tn+ is corrected to $\mathbf{4 6 3}$. See revised table below.

- On page E5, the first paragraph in the "Outcomes of Studies with Corresponding Troponin+ and Troponin-" section beginning with the fifth sentence should read as follows):

*Address for correspondence: Omar S. Darwish, MS, DO, University of California, Irvine, UCI Medical Center, 101 The City Drive South; Building 26, Orange, CA 92868; Telephone: 714-887-4809; E-mail:odarwish@uci.edu

(C) 2018 Society of Hospital Medicine DOI 10.12788/jhm.3060
"In the pooled data, 463 (67\%) patients tested negative for troponin and 228 (33\%) tested positive. The overall mortality (from sensitivity analysis) including in-hospital, 30-day, and 90day mortalities was $1.2 \%$. The NPVs for all individual studies and the overall NPV are 1 or approximately 1 . The overall PPVs and by study were low, ranging from 0 to 0.60 . The PLRs and NLRs were not estimated for an outcome within an individual study if none of the patients experienced the outcome. When outcomes were only observed among troponin-negative patients, such as in the study of Moore (2009) who used 30-day all-cause mortality, the PLR had a value of zero. When outcomes were only observed among troponin-positive patients, as for 30-day all-cause mortality in the $\mathrm{Hakemi}^{9}(2015)$, Lauque ${ }^{10}$ (2014), and Lankeit ${ }^{16}$ (2011) studies, the NLR had a value of zero. For zero cells, a continuity correction of 0.5 was applied. The pooled likelihood ratios (LRs) for all-cause mortality were positive LR 2.04 [95\% Cl, 1.53 to 2.72] and negative LR $\mathbf{0 . 7 2}$ [95\% Cl, 0.37 to 1.40$]$. The OR for all-cause mortality was 4.79 [95\% Cl 1.11 to $20.68, P=.0357]$.

TABLE 2. Summary Measures of the Association between Troponin Classification and Overall 30-day All-cause Mortality and Stratified by Study

\begin{tabular}{|c|c|c|c|c|c|c|c|c|c|c|c|c|}
\hline \multirow[b]{2}{*}{ Source } & \multirow[b]{2}{*}{ Low-risk } & \multirow[b]{2}{*}{$\mathrm{Tn}+$} & \multirow[b]{2}{*}{ Tn- } & \multirow[b]{2}{*}{ PPV } & \multirow[b]{2}{*}{ NPV } & & & \multirow{2}{*}{\multicolumn{2}{|c|}{$\begin{array}{c}\text { NLR }(95 \% \mathrm{CI}) \\
\text { OR }\end{array}$}} & \multicolumn{3}{|c|}{ Odds Ratio } \\
\hline & & & & & & \multicolumn{2}{|c|}{ PLR $(95 \% \mathrm{Cl})$} & & & OR & $(95 \% \mathrm{Cl})$ & $P$ Value \\
\hline Ozsu et al. ${ }^{8}$ & 57 & 5 & 52 & & & & & & & & & \\
\hline 90-day mortality & 4 & 3 & 1 & 0.60 & 0.98 & 19.88 & $(4.56-86.66)$ & 0.26 & $(0.05-1.42)$ & 76.50 & $(5.31-1102.4)$ & .0014 \\
\hline Hakemi et al. ${ }^{9}$ & 173 & 84 & 89 & & & & & & & & & \\
\hline In-hospital mortality & 4 & 4 & 0 & 0.05 & 1.00 & 1.90 & $(1.36-2.65)$ & 0.19 & $(0.01-2.64)$ & 10.01 & $(0.53-188.75)$ & .1243 \\
\hline Lauque et al. ${ }^{10}$ & 84 & 17 & 67 & & & & & & & & & \\
\hline 30-day mortality & 1 & 1 & 0 & 0.06 & 1.00 & 3.82 & $(1.54-9.48)$ & 0.31 & $(0.03-3.44)$ & 12.27 & $(0.48-315.11)$ & .1300 \\
\hline Ozsu et al. ${ }^{13}$ & 45 & 14 & 31 & & & & & & & & & \\
\hline 30-day mortality & 0 & 0 & 0 & 0.00 & 1.00 & 1.59 & $(0.21-11.79)$ & 0.73 & $(0.10-5.23)$ & 2.17 & $(0.04-114.99)$ & .7016 \\
\hline Sanchez et al. ${ }^{14}$ & 329 & 44 & 278 & & & & & & & & & \\
\hline 30-day mortality & 2 & NS & NS & NS & NS & NS & - & NS & - & NS & - & - \\
\hline Lankeit et al. ${ }^{16}$ & 198 & 71 & 127 & & & & & & & & & \\
\hline 30-day mortality & 1 & 1 & 0 & 0.01 & 1.00 & 2.11 & $(0.93-4.79)$ & 0.39 & $(0.04-4.29)$ & 5.43 & $(0.22-134.95)$ & .3024 \\
\hline Moores et al. ${ }^{22}$ & 191 & 42 & 149 & & & & & & & & & \\
\hline 30-day mortality & 1 & 0 & 1 & 0.00 & 0.99 & 1.12 & $(0.10-12.57)$ & 0.97 & $(0.43-2.16)$ & 1.16 & $(0.05-29.11)$ & .9260 \\
\hline All studies pooled ${ }^{a}$ & 691 & 228 & 463 & & & & & & & & & \\
\hline 30-day mortality & 7 & 6 & 1 & 0.03 & 1.00 & 2.04 & $(1.53-2.72)$ & 0.72 & $(0.37-1.40)$ & 4.79 & $(1.11-20.68)$ & .0357 \\
\hline Sensitivity Analysisc & & & & & & 3.40 & $(1.81-6.37)$ & 0.59 & $(0.33-1.08)$ & 11.01 & $(3.38-35.92)$ & $<.0001$ \\
\hline
\end{tabular}

